\title{
Implications of Termination for the Pastoral Counseling "Contract"
}

\section{Introduction}

"A time to be born, and a time to die; a time to plant, and a time to pluck up what is planted." (Eccles. 3:2) Perhaps Koheleth was suggesting that there is a time under heaven not only for beginnings but for endings. Endings, we need to remind ourselves, can mark fulfillment, fruition, and climax. Termination in pastoral counseling as in other forms of psychotherapy suggests "there is a time to begin and a time to end." Without an understanding of termination in the pastoral counseling relationship the effectiveness of that ministry is seriously handicapped. Pastors may offer support, confrontation, concern and insight. But only to say "go into peace," or "return to your home and your people as witness to the wholeness of self you have experienced," may miss a final opportunity offered by the termination phase.

A review of the literature in the pastoral counseling field indicates an almost total absence of this crucial, climactic area of the pastor's opportunity in his counseling ministry. This article is addressed to the needs of the pastor who may wish to sharpen his counseling skill at an often unnoticed but decisive point-termination. Only a beginning
ROBERT L. NEW'TON

Professor of Religion

Campbell College

Buie's Creek, North Carolina

and

EDGAR DRAPER, M.D.

Protessor of Psychiatry and

Director of Resident Education

University of Michigan

Medical School

Ann Arbor, Michigan

has been made, important questions raised, and possible directions noted.

The following cases point to the possibility of termination being a source of fulfilling the counseling "contract" through or even because of the "time to pluck up what is planted."

A campus pastor might detect in the struggle of this coed's emancipation from counseling a specific pattern involved in her dependence on parents.

A girl who was very happy about what had been achieved in counseling spent several sessions inconclusively weighing pros and cons of terminating.. The counselor finally communicated to the student her impression, that though not sure of her reasons, she really wanted to leave, and wondered why she could not just act on this wish; she could always return if she 
wanted.* The student after a moment of silence exclaimed with smiles and tears that she just realized that this was what she had always wanted her mother to say to her. She was then able to express the feelings that had been an obstacle to leaving the coun. selor: "We come here one after another with our problems and miseries, and when we leave happy - what reward do you get for the trouble you took? It isn't fair to you!" She left this last session with the feeling that her growing up would not leave her parents without any reward, nor herself without any affectionate ties to the family. ${ }^{1}$

A forty-year-old woman who was moving beyond a "presenting problem" of domestic difficulty to "working through" certain religious material found her feelings about termination meaningful to new understanding.

Mrs. W.: I know, when you told me a few weeks ago that there was going to be an end to this, it came as quite a shock because (laughs) I thought this was going to go on forever. I realized too, then, how much I really was leaning on you and drawing from your strength. I think the realization that this was going to end brought a moment when I was a little frightened. I thought-well, how am I going to handle it alone without this support that I had been getting. And for a few seconds I really thought II can't even think-it's going-it's going to be an empty world.

Mr. C.: A real threat to you.

Mrs. W.: It frightened me, momentarily, and however, I think-I-in fact, I've gotten over that. I realized that what I had gained is going to be intensely helpful.

She was facing the idea of their termination, and yet she still found it threatening. As Mr. C had already done

* One of a variety of possible termination arrangements.

1 Hanfmann, Jones, Baker and Kovar, Psychological Counseling in a Small College (Cambridge: Schenkman Publishing Company, 1963), p. 93. at the very beginning, he told her again that, this termination point was arbitrary and that he would be willing to see her further if she so wished. At this point she seemed visibly to relax, saying she would return if it seemed wise. It was not the idea of planning a specific return, but the notion that she could plan it, which had the relaxing effect. This kind of response was fairly typical of a number of other persons counseled in the church context. ${ }^{2}$

Usually the working pastor is a "one man staff" in the counseling ministry offered by the church he serves. As we shall see, the persons with whom he counsels and their problems are similar to those of the study underlying this article. It is our contention that psychotherapy and its literature have many insights about termination which are translatable into the context of pastoral counseling. These insights can furnish helpful direction to the sensitive pastor in completing his counseling ministry to persons.

The ministry to those seeking counsel can be significantly enhanced if termination is understood and utilized in the total context of counseling. Included in this relationship would be assessment, the setting of goals, and the establishment of a "contract." The Biblical concept of "covenant" has rich potential in this regard.

A central conviction of this article concerns the decisiveness of successful termination for maturity and wholeness. Menninger's words about the analyst could apply to the pastor's task as well: "By not giving me what I thought I wanted from him, the analyst gave me what I needed; namely, a better selfunderstanding, a better capacity for dis-

${ }^{2}$ Seward Hiltner and Lowell G. Colston, The Context of Pastoral Counseling (New York: Abingdon Press, 1961), pp. 124-125. 
crimination, a greater tolerance for unavoidable dissatisfaction, a clearer view of my needs. In a symbolic sense, the analyst has given me himself, and I felt free to take his gift. I do not need his help anymore ... I can substitute hoping for despairing, enjoying for expecting, giving for taking. I can endure forgoing what must be forgone and accept and enjoy without guilt such pleasures as are accessible to me."

Edelson notes, "Successful terminations, from which answers to important questions might be induced, are infrequent," adding that little is known about the work of colleagues. He calls what happens when analysis terminates a new beginning. Note of the importance of termination's implications for the pastor-parishioner relationship calls attention to the meaning of its ending. There are possible, for instance, feelings of rejection, "backsliding" (shades of regression), mourning over the loss of a meaningful relationship of the past, and new freedoms. The work of the ministry does include these risks and opportunities.

Edelson also points out that in a successful termination there is an "unconditional expectation of being loved without being under any obligation to give anything in return." Shifting to the language of metaphor he concludes, "If this process can develop in an undisturbed way ... the patient feels that he is going through a kind of rebirth into a new life, that he has arrived at the end of a dark tunnel, that he sees light again after a long journey, that he has been given a new life; he experiences a

is Menninger, Karl, Theory of Psychoanalytic Technique (New York: Harper Torchbooks, 1958), p. 159.

4 M. Edelson, The Termination of Intensive Psychotherapy (Springfield: C. C Thomas, 1963), p. 4. sense of great freedom as if a heavy burden has been taken from him, etc. It is a deeply moving experience (this) taking leave ... sincere and deeply felt grief is mitigated by the feeling of security; originating from the newly-won possibilities for real happiness." contains an echo of the pastor's finest goals and deepest intent. Parallels there are in termination of pastoral counseling.

However, the pastor's relationship to the people he serves needs to be distinguished from that of other therapists at several significant points. His continuing relationship with his parishioners makes unlikely a chasmal referral. Termination is never complete for the same reason-there is no discontinuance of the relationship in other settings. Usually the counselee is not new to the pastor who has come to know him through the breadth of the church's life. In summary, the pastor seldom sees the person only in his role as a counselor. However, the overall involvement in the life of the parishioner makes related outcomes possible even though short-term counseling is the general mode. The insights and approach of related fields addressing problems of psychological health has been instructive in other aspects of pastoral counseling. Why not in the termination issue?

Support for this conviction is found in our study of psychiatric case materials made available from the records of Billings Hospital, Psychiatric Outpatient Department, University of Chicago Clinics. Examination of 216 record cards of patients who came through the out-patient psychiatric clinic in 1967 provided twenty-two cases chosen for study. Criteria for the selection of these particular cases were fourfold:

${ }^{5}$ Ibid., pp. 2-4. 
1. The cases chosen had been accepted by the clinic for treatment.

2. These cases were all treated in short-term therapy and the persons involved were judged to be the sort of counselees who might appear in the pastoral counselor's study. Length of therapy ranged from two sessions to approximately thirty.

3. Termination summaries were available to determine the conditions which prompted the therapist to terminate.

4. Availability and adequacy of records was a requirement.

The following table indicates the range of presenting problems, therapeutic assessments, and types of termination emerging from the study. This profile when compared with other studies indicates a striking parallel to the types of psychic problems people bring to the well-trained pastoral counselor.

\section{PRESENTING PRORLEMS}

Psychosomatic complaints

Threatening suicide

Family (marital problems)

Depressed

Alcoholic (drinking problem)

Communication problems

Nervous (anxiety)

Personal problems (can't take responsibility, inability to work, absenteeism)

Psychotic

From assessment of therapists, most appeared to be (psycho) neurotic.

One such study by Hiltner and Colston contained twenty-five cases in the context of pastoral counseling which were electronically recorded and presented in varying detail. The lack of specific reference to termination's significance in pastoral counseling literature and practice is typical in these materials, but the case materials themselves provide implications for this study.

With the profile emerging from the Billings study and the Hiltner-Colston study as guides, we focus upon the manner in which termination was handled and its relationship to psychotherapy's full potential. Suggestive relationships between psychotherapy and pastoral counseling present themselves at numerous points. "As a guide to the pastor, types of termination will be noted and the question of criteria for termination and its management will be raised. Decisive to this crucial latter question are the attitudes and feelings of the counselee towards the pastor with reverse attitudes deserving equal notice. We will be drawing briefly on any implications which the concepts of transference and counter-transference might have for short-term pastoral counseling. (A sim. plistic definition of transference serves our purposes, namely, the counselee's attitudinal and emotional "leftovers" of past, especially early, experiences that mantle the therapist. Counter-transferences are similar reactions of the therapist to his patient or counselee.)

\section{Termination Data}

\section{"Presenting Problems" \\ of the Counselees}

Perhaps the most useful material to our study in its relationship to pastoral counseling is the focus on the "presenting problems," i.e. the problem as presented by the patient as the occasion for coming. The chart above indicates the impressive similarity of psychic problem areas to those confronting the pastoral counselor. Those problems related to marriage and family communication, alcoholism, anxiety, and depres. sion have been a traditional challenge to pastoral responsibility as long as the

* Comparison of the data from the Billings' study and the Hiltner and Colston study underscores the similarity of counselees and the problem areas which were confronted in both instances. 
role has existed. Psychosomatic complaints are frequently brought to the pastor's attention. Threatened suicide often requires psychiatric consultation, although the pastoral role and counsel often prove a natural on-going resource. Most of the cases in our study appeared to be in the neurotic category. Only one appeared to be confirmed as psychotic. (In several more the case materials suggested psychotic tendencies.) The cases in the Hiltner and Colston study reflected a similar ratio. In summary, it is interesting to note the commonality of content in these cases and those the well-trained, perceptive pastor encounters in the average American community.

\section{The Setting of Termination}

Although our focus is on termination, this climactic aspect of counseling cannot be understood without viewing it against the background of clinical or pastoral assessment, the setting of goals. and the unfolding psychodynamics of the "contract." All of these hopefully come to fruition in a significant experience of termination. Consequently, a brief word concerning these interrelated aspects of psychotherapy is indicated.

\section{Pastoral Assessment}

In Chapter Two of Psychiatry and Pastoral Care, Draper has succinctly dealt with the need for careful "Pastoral Diagnosis." After enumerating a num. ber of characteristics that reflect the strength or weakness of the self he notes three diagnostic vectors. These are designated as "the call for help, the call for help to the minister, and the call for help to the minister now." As questions they become, "What is the trouble?" "Why come to me?" "Why come now?" An-

6 Draper, Edgar, Psychiatry and Pastoral. Care (Englewood Cliffs: Prentice-Hall, 1965), p. 60 . swers to these questions not only help arrive at precise diagnosis, but also furnish an initial but decisive step toward successful termination.

\section{Establishment of Approach and Methods}

Mutually agreed upon methods of achieving the reasonable goals consequent to assessment are essential to the "contract," and contribute crucially to its termination. Four types of appointment structure help set the course toward termination in counseling.

1. For some counselees the specific number of sessions can be agreed on in attempting to meet specified goals. (In the Hiltner and Colston study, "All per sons were told that we were prepared to counsel with them according to their conception of its helpfulness, up to twenty interviews without further arrangement ... we made it clear that it might continue longer as desired and needed." ${ }^{7}$ Even though clearly stated and repeated early, it has been our experience that patients or counselees promptly forget a specified number of sessions or the date of termination. Quitting at the agreed time has unique advantages to be mentioned later.

2. For other counselees a specific number of sessions may not be initially feasible, but when certain goals are met as to the individual's improved functioning, termination ensues. Although initial flexibility may be indicated, clearly agreed upon dates to stop in the future must be set with time for termination work to be done.

3. Goals may be more limited ones related to a crisis situation, i.e. acute alcoholic episode, attempted suicide, losses, etc. To help see the person through the crisis of the moment may dictate a provisional termination with

${ }^{7}$ Hiltner and Colston, op. cit., p. 19. 
his return to adequate functioning.

4. A counselee requiring periodic help may have limited goals set which, when realized, lead to an open-ended "termination." This counselee, the pastor or other therapist may assess, will be incapable of meeting the demands of life without supportive therapy and a final termination may be contraindicated. A sensitive pastor can represent "this present help in time of trouble," without invoking the "tar-baby syndrome." (Most parish ministers encounter counselees who "sticketh closer than a brother" and whose insatiable needs may be difficult if not impossible to satisfy. A few such parishioners can monopolize his time, preventing a needed ministry to others, and without real help effected to the "ever hungry ones.")

\section{The "Contract" or Covenant}

The scope of this article permits only a brief outline of the covenantal elements involved in the "contract." It is necessary to note them as essential to an understanding of the contract's termination.

1. "In psychotherapy," as Karl Menninger notes, "the relationships between the two parties come very close to being the goal themselves. They are by no means incidental (nor) in the strict sense of the word a vehicle for the transaction. The relationships are the most tangible elements of the transaction." This is also true in a significant pastoral relationship. The perspective of the Christian ministry implies a relationship from which one considers any interior problem from the vantage point of ultimate as well as proximate concerns. However, for counseling it is always ad-

\footnotetext{
${ }^{8}$ Draper, op. cit., p. 92.

${ }^{9}$ Menninger, op. cit., p. 22.
}

visable to ask, "Establish a relationship in order to do what?" With some parishioners establishing a relationship of meaning and investment may be the primary goal, but if so, the counselor should know that, and be content without "waking sleeping dogs."

2. Another element of the therapeutic transaction distinguishing it is its openendedness. To use Freud's comparison in a late work, therapy is terminable but, paradoxically, interminable. ${ }^{10}$ One may set a seemingly defined goal such as "finishing college." However, learning itself can never be completed. "In a way, the termination of the contract in psychotherapy is decided upon retrospectively, when the patient decides that from now on he can decide alone, but even then this decision will be no more than a venture."11 Here we are speaking of therapy's having opened certain vistas or doors in the person without the therapist's need to hang on or lead the person through by unnecessary continued "work." 12

3. A further factor influencing the nature of the contract involves the people in the counselee's sphere of living. The transaction may focus on two parties but is not necessarily limited to them. As already noted at the point of initial contacts the counselee's spouse, parents, an older son or daughter, etc., make up the human elements in his environment. The covenant concept may be more appropriate to pastoral counseling including, as it does, a broader corporate familial and cultural setting

${ }^{10}$ Freud, Sigmund, "Analysis Terminable and Interminable," International Journal of Psycho-Analysis, Vol. 18, 1937.

11 Menninger, op. cit., p. 23.

12 Maria Kramer, "On the Continuation of the Analytic Process after Psychoanalysis (A Self-Observation)," International Journal of Psychoanalysis, 40:17-25, 1959. 
for the individual's life. The pastor needs little reminder of the entangled skein of human relationships which complicate the problem! Cooperative relationship with a range of resource persons, i.e. physicians, social workers, family life agency personnel, lawyers, etc., heightens the pastor's opportunity to counsel more effectively. The contract then may be a triangular, polygonal, or even a congregational one.

4. The above aspects of contract all imply some degree of "carry over." There are times, however, when carry over may preempt a solution to a counseling problem. If that problem happens to be unresolved grief, for instance, permitting a carry over aborts the opportunity to work through the older, hidden but still live loss by diminishing the potency of the termination itself. ${ }^{13}$ Thus, either by continuing counseling, referral, or by invoking any method which does not end the relationship in a clear and clean-cut manner, the work on separation conflicts is compromised. For instance, for the counselee to say "she could always return if she wanted" (pages 7,8 ) could offer a soothing but destructive intrusion on the grief work. ${ }^{14}$

\section{Termination}

\section{Factors Useful in a \\ Consideration of Termination}

The continuing wisdom of Freud's two conditions for termination of analytic cases has its carry over for counseling as well:

13 Freud, Sigmund, "Mourning and Melancholia," Standard Edition 14:237-258, 1957. Also in Collected Papers 4:152-170, 1925.

${ }^{14}$ Freud, Sigmund, "Remembering, Repeating and Working-Through (Further Recommendations of the Technique of Psycho-Analysis, II)," Standard Edition 12:145-146, 1958. Also in Collected Papers 2:366-376, 1924.
First the patient must no longer be suffering from his former symptoms and must have overcome his various anxieties and inhibitions and, secondly, the analyst must have formed the opinion ... that no repetition of the patient's pathologic processes is to be féared. ${ }^{15}$

Freud was more skeptical about the achievement of the second condition which in éssence involves an improvement in functioning and internal alteration ("structural change") of a prophylactic potency.

Dr. Harold Hiatt's review of criteria for termination of psychotherapy may serve as useful "signs" for the pastor as well as psychotherapist. ${ }^{16}$

A. When termination is considered the counselee should reflect the following:

1. A more successful handling of symptoms. This may be reflected in the interviews by apologetic references, or none at all, to the initial symptoms.

2. Less inhibition in his speech, association of ideas, and motor movements.

3. Reduction in the number of guiltpunishment sequences.

4. "Surprises" in the strength of his personal relationships.

5. Loosening the misbehavior patterns frequently demonstrated in the interviews, for instance, coming late or being a "hanger on" (i.e., "one question before I leave").

6. Good tolerance of the necessary interruptions of therapy, such as necessary postponements and vacations.

${ }^{15}$ Freud, Sigmund, "Analysis Terminable and İnterminable," p. 373.

${ }^{16}$ Harold Hiatt, "The Problem of Termination of Psychotherapy," American Journal of Psychotherapy, Vol. XIX, No. 4 (October, 1965), pp. 609-611. 
7. Openness as to impressions or misunderstandings of the pastoral coun. selor.

8. Less forgetfulness, particularly of important data.

9. Increased satisfaction in work performance.

10. Tolerance of anxiety, hostility, sexuality, dependence, or lack of openness in others. Equally evident should be a greater comfort in setting limits on the behavior of others that should not be tolerated.

Łl. Resourcefulness in the use of free time.

12. A reduction in the use of superlatives, if these had been overdone.

13. An enhanced feeling of choice about daily rituals, particularly where compulsion about some have been present. The more or less hysterical patient may begin to show need for minimum structure or orderliness, perhaps even ritual.

14. Active role in the family constellation.

15. Spontaneous consistency in his sex. ual performance or a tolerance of improvement in this area.

16. An ability to laugh at himself, in a way that invites others to join in.

17. Increased interest in termination.

B. The pastoral counselor should consider termination when he experiences:

1. A genuine upsurge in feelings concerning the basic capacity of the counselee for responsive human emotions.

2. Respect for the emotional strength of the counselee, and a confidence he has "learned something."

3. A contrast between the parishioner's problems when the treatment was initiated and his current problems.

4. Confidence that the counselee can handle future stressful situations.
5. A feeling that he (the counselor) has learned something new about a person or a psychological process.

6. A pleasant anticipation of the approaching hour (like standing back enjoying a job well done) or, paradoxically, previous unnoticed reactions of boredom, sadness of anticipated loss, sexual attraction, or feelings of competitiveness with the patient.

7. A decrease in feeling "on guard" with consequent increase in spontaneity and feelings of freedom.

C. Termination should be discouraged if after a sufficiently long period of counseling the following problems arise:

1. Chronic disagreement over date or time of the appointment, or provoca. tively missed or canceled appointments. (These may be cries of need, transference signals, or the result of counter-transference mistakes in the immediately preceding interview.)

2. Sudden shifts to a superficial discussion of problems or a denial of all problems. This is often reflected in a reporting (sometimes belabored) of the chronology of happenings between interviews.

3. A desire to leave the pastor before he (the counselee) is "abandoned."

4. An over-relating, for instance at the social level, beyond the counseling (this is particularly tricky for the pastor), or the reverse, "I never want to see you again."

An example of improved functioning and emancipation in one of our case studies illustrates the patient's readiness. The patient entered the hospital after a suicidal attempt which followed a violent family quarrel. One goal of therapy was to help the patient improve her controls of violent behavior toward others and 
herself. A developing positive transference, coupled with a change in circumstances, was used to encourage non-destructive outlets for her energy. The obsessive compulsive tendencies characterizing her psychoneurotic personality were channeled into enhanced function. ing. Increased self-esteem was in evidence as therapy proceeded. She found a job in which she was content. Physical fights with her husband stopped. Peace and communication were established with her parents, toward whom she had revealed hostility and guilt at the beginning of therapy. Delinquency in attending the early terminating sessions appeared as her defensive way of showing needed independence from the therapist, and "reattachment" to her husband. When her avoidance was worked out, termination by mutual consent followed.

As noted, all the cases in the HiltnerColston study were terminated by prior agreement; that is, the goals and length of counseling were clearly delineated. Several cases in our study reflected this category. A male patient was diagnosed as suffering depression with heavy involutional overtones. He spoke of emptiness of life and discontent with his job. As a consequence, he was increasingly unable to work. Suicidal risk was present. As therapy proceeded, the patient's mood improved considerably as he became steadily less depressed. He returned to work. His acceptance of a three-month limitation on therapy with no evident sense of rejection was an important sign of improvement.

In his study of analytic cases forced to terminate by his leaving, Dr. Paul A. DeWald ${ }^{17}$ noted that no patients who

17 Paul A. DeWald, "Reactions to the Forced Termination of Therapy," The Psychiatric: Quarterly, (Utica: State Hospitals Press, Jan., 1965). began therapy knowing in advance of the anticipated termination experienced "intense or striking affective response." A sense of rejection or abandonment is usually not felt by patients who experience termination actively and participate in its timing.

In some instances, the therapy sessions close without notice. They "die out" or "just fade away" as a clear sign of de facto termination. This was true in one of our selected patients and two counselees in the comparative study. A female patient exhibited inability to make decisions, and apprehension regarding the future. She had an emotionally unhappy and sexually unfulfilling relationship with a man whose possible loss precipitated a suicide attempt with drugs. A poor self-image proved almost totally self-incapacitating. Inability to empathize with others characterized her relationships. As her twenty-six sessions unfolded, some improvement was noted. A better job and improved relationships with persons at work signified possible improved functions. However, the therapist missed one session and the patient did not return. She left her check before she departed, but gave no forwarding address.

Such sudden (or even more gradual) departures can furnish dramatic evidence of what has been called "the narcissistic wound" in some.

The primary experience for the patjent on the level of the narcissistic wound is: something is being done to me! Feeling abandoned, his sense of superiority and omnipotence wavers . . . Suddenly the patient is wrenched by the awareness: "there are things in the world I can do nothing about even though they hurt me very much'... The patient may respond to this trauma with a profound sense of worthlessness and a subsequent hopelessness and apathy; with panic and frantic attempts to control his experience; or with rage. ${ }^{18}$

${ }^{18}$ Edelson, op. cit., pp. 34-35. 
The pastoral counselor then must be sensitive to the background and meaning of separation in the life of this counselee. Has this person lost a "significant other" in his life which heightens the trauma of separation symbolized by termination? In such cases termination must be even more carefully "worked through" Jest the covenant be threatened or abandoned. Any sense of "being left" by the counselor can undo apparent gains. (In such situations transference reactions serve as reexperiencings of the separation in the original loss.) DeWald's generalization is a useful guideline: " the greater the degree of transference involvement in the patient, the more intense will be the neurotic components of the reaction to termination." 19

Forced termination was not evidenced in our study, but was present in the comparative study in three instances. On occasion, practical reasons require termination. External factors in the life of the parishioner or of the pastor, such as illness, a move to a different community, etc., end the counseling relationship. A case in point was a liêutenant in the Army. He expected to be transferred to a distant post in a few months and requested short-term but inténsive counseling. His transfer came earlier than expected. Consequently, he was able to have only eleven interviews before leaving Chicago. With such situations "where fate steps in," the opportunity for working at termination problems should not be by-passed.

In approximately one-fourth of the cases in both studies the termination was

19 Paul A. DeWald, "The Termination of Psychotherapy," Psychiatry Digest, Vol. 28, (October, 1967), pp. 33-46 and "Forced Termination of Psychoanalysis," Bulletin of the Menninger Clinic, Vol, 30, No. 2, (March 1966), pp. 98-110. left open-ended. This "closure" is utilized when the prognosis suggests the wisdom of continued availability by the counselor and periodic supportive therapy. A compulsive but psychotic patient was seen twelve times for help in dealing with an unexplained anxiety and moderate depression for which she had been hospitalized twice previously. Treatment primarily involved utilizing quickly developing positive transference that placed the therapist in a respected, guid. ing role of "mothering figure." Small inroads were made in helping the patient see she could alter some of her selected life patterns. "Insights" into possible sources of depression and reasonable solutions to immediate life situations were discussed with benefit. However, a sixty-year history of conflict suggested that supportive therapy during recurring depressions would be required.

A twenty-eight-year-old woman, when asked about future help, said she would try on her own to exploit insights gained, set more realistic future goals, and make efforts at opening new lines of communication with her husband in place of hostility toward him. If things did not go well she would seek further help.

As to management of those who appear to need "interminable counseling," active devices may be used to help the counselee maintain indentification with the pastoral counselor without overwhelming impositions or "tar-baby" terminations. If a positive transference is established, ordinary exposures and visibilities may do a great deal for the comfort of the parishioner. The pastor may offer reassurance that he will be available should further contact be needed, but only when really needed. Continuing interest in the parishioner can be made plain without interviews or prolonged personal contact. He may be encouraged to write the pastor informing him of progress at some future time. An offer 
of a specific time for a return àppointment could be meaningful, even if for some distant date. Feelings of separation and possible mobilization of conflicts are minimized. Thus the intensity that the stress termination unconsciously represents is reduced.

These techniques tend to maintain positive transference at a level which can prove supporting to the parishioner in the future. Some persons cannot function adequately without a significant transference relationship; it is wiser for these counselees not to view counseling as terminated but interrupted. Others may be unable to endure even this. They will require occasional visits over prolonged periods of time to keep them functioning without further deterioration.

Two clinical phenomena familiar to experienced psychotherapists are called "flight into health" and "transference cure." The former is a resolution, though often transient, of a disabling conflict that suddenly frees a patient. He feels "well" and usually leaves treatment either because of an unwitting move away from an undesired confrontation in the therapy, or because some external event offers an apparent "easy" solution. A "transference cure" is a special kind of flight-into-health reaction secondary to a positive or an omnipotent transference experienced by a patient that is sufficient to make him feel cured by its potency, like an adolescent "in love."

The very inexperienced therapist may simply be deceived by such reactions. A slightly more experienced therapist will not be deceived by his own "omnipotence" but will be tempted to undercut such experiences. The very experienced therapist will recognize these phenomena and will only undercut them if a better alternative is within the patient's capability. Only such a perspective can guide appropriate termination moves in these situations.

A date for termination should be set sufficiently far ahead to permit adequate time for exposure and resolution of contractual issues, conflicts, or resistance surrounding termination. For healthier parishioners, termination conflicts require verbalization and active attention and expression from the counselor when possible. Feelings of resistance and defenses (e.g. denial) against termination require mobilization. The counselee will need help in integrating them and resolving them consciously in relation to the counselor. This "working through" requires a reasonable length of time, from one to four months, depending on the strength of the relationship, total length of counseling, the opportunities afforded by termination itself, and the contractual goals.

In those cases where exploration of underlying conflicts has been minimal and when supportive counseling has been directed toward the undergirding of defenses, the strategy of allowing termination time should pertain. However, previously unnoted unconscious reactions usually should not be exposed or explored at the end. Reinforcement and reward may be actively used to strengthen the individual's motivation toward termination. Positive rapport with these persons is vital. This supporting force is to be kept alive after counseling sessions have terminated, except as heretofore noted.

As termination takes place, both counselee and pastoral counselor will respond with feelings and actions which are reflective of the process. These signs should be understood and utilized. Various means of avoiding the loss, consequent grief, or separation worries may be attempted. To escape the conflicts or hurt already mentioned, some counselees 
will want to terminate immediately. In others, slight recurrence of symptoms or mild regressive moves $^{20}$ may only signify readiness to terminate and should not dissuade the therapist from the final date. Others may bring up new problems for discussion as a means of expressing the desire to extend the contract. Some may begin a search for a substitute to take the pastoral counselor's place, prolonging the hope for gratification from a new transference figure. An alternative to this search may occur through fantasy of some form of continuing contact with the pastor on a social basis or in some occult capacity. A counselee's "sour grapes" depreciation of the counseling and its results may provide reassurance to the recipient that nothing of real value or significance is being lost.

The pastor, too, is not free of his own reactions to termination. He may encourage or indirectly provoke early and premature termination as an expression of unwillingness to become party to a lengthy and involved relationship. A reluctance to separate from a counselee represents the other extreme. Termination may be avoided or delayed too long due to umrealistically ambitious or perfectionistic goals for the parishioner. Can the pastor's self-image endure a counselee's hostility or depression when facing termination without threatening anxiety or guilt? Is there an over-identification with this particular person due to significant separation or loss experiences of his own? The counselor's meth-

20 Alexander, Franz. "The Voice of the Intellect is Soft," Psychoanalytic Review 28:1229,1941 . odology (or lack of it) of termination may hint of his own areas of termination conflict. Derailment of termination by waiting until the counseling "runs down" or the counselee "wears out" is another avoidance technique. Another is to "spring" termination on the counselee suddenly, avoiding reactions by its rapidity and unexpected nature. Forced termination is sometimes evaded by automatic referral.

Finally, continuance of the sessions at their regular frequency to the very day of termination ${ }^{21}$ will tend to intensify the work involved in its successful outcome. A "tapering off" approach may reduce the intensity and opportunity offered by termination's impact. Such approaches have been too often routinely used by therapists as a means of handling their own termination problems, e.g. fears of a "showdown," patient's anger, unrealistic protective concerns or personal incapacities for final goodbyes. In any of these circumstances, the pastor suffers inability to detect and work with the counselee's responses to termination.

In summary, for the pastoral counselor who is sensitive to the issues and possibilities of termination, counseling effectiveness can be increased during and through this critical phase of counseling. This article points to the possibilities of therapeutic development not alone by the setting of goals and the establishment of covenant relationships, but by moving to new beginnings through wise termination management.

\footnotetext{
21. Lipton, Samuel, "The Last Hour," Journal of the American Psychoanalytic Association. 1951.
}

$\mathbf{T}$ THE transformation of the Christian faith from a justifying faith into a belief in truths means that a 'Christian' utopia has replaced the reality of salvation as preserved by faith. But the true Christian demand or commandment can only be fulfilled on the basis of this reality in which God turns to men, raising them from the dead and making them whole, that is, making them his sons-FriedricH. Gocarter, Despair and Hope for Our Time, Pilgrim Press, 1970. 